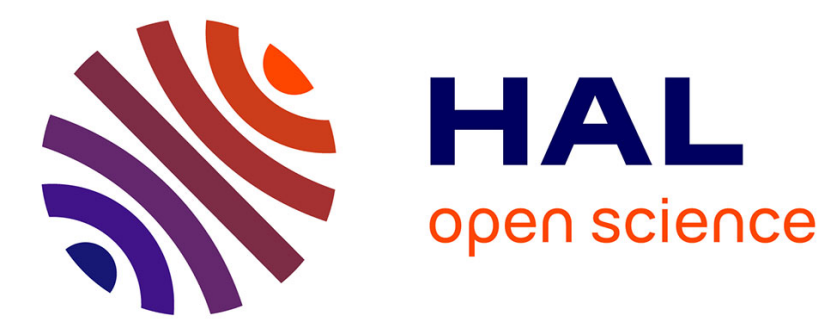

\title{
INTERGRANULAR CORROSION OF SINGLE PHASE ALUMINIUM AS A PITTING PHENOMENON
}

\author{
M. Metzger
}

\section{> To cite this version:}

M. Metzger. INTERGRANULAR CORROSION OF SINGLE PHASE ALUMINIUM AS A PITTING PHENOMENON. Journal de Physique Colloques, 1975, 36 (C4), pp.C4-387-C4-393. 10.1051/jphyscol:1975439 . jpa-00216345

\section{HAL Id: jpa-00216345 https://hal.science/jpa-00216345}

Submitted on 1 Jan 1975

HAL is a multi-disciplinary open access archive for the deposit and dissemination of scientific research documents, whether they are published or not. The documents may come from teaching and research institutions in France or abroad, or from public or private research centers.
L'archive ouverte pluridisciplinaire HAL, est destinée au dépôt et à la diffusion de documents scientifiques de niveau recherche, publiés ou non, émanant des établissements d'enseignement et de recherche français ou étrangers, des laboratoires publics ou privés. 


\title{
INTERGRANULAR CORROSION OF SINGLE PHASE ALUMINIUM AS A PITTING PHENOMENON
}

\author{
M. METZGER \\ Department of Metallurgy and Mining and Materials Research Laboratory \\ University of lllinois at Urbana-Champaign \\ Urbana, Illinois 61801, U.S.A.
}

\begin{abstract}
Résumé. - Les données relatives à l'attaque intergranulaire fissurante dans l'aluminium pur par l'acide chlorhydrique sont rappelées. Des études électrochimiques et morphologiques de la corrosion par piqûres dans l'acide sulfurique contenant du chlorure de sodium sont décrites.

Une attaque intergranulaire fissurante a été produite dans ce milieu et une interprétation est présentée concernant les rôles joués par le chlorure et par la teneur du métal en cuivre, dans ce mode d'attaque.
\end{abstract}

Abstract. - The characteristics of the intergranular fissuring phenomenon long known for aluminium in hydrochloric acid were reviewed. Electrochemical and morphological studies of pitting corrosion in sulfuric acid containing sodium chloride were described. Intergranular fissuring was reproduced in these solutions and an interpretation given of the roles of chloride ion and copper content in producing this type of attack.

The intergranular corrosion phenomena which are exhibited by high purity aluminium exposed to hydrochloric acid have received attention from a number of researchers since the first report in 1934 [1]. Most of the interest apparently originated in the hope of obtaining insight into metallurgical questions - the properties of grain boundaries, possible segregation phenomena, the properties of aluminium. The present work takes a more electrochemical approach. The rapid intergranular fissuring which occurs under certain conditions is a type of pitting phenomenon, and it was sought to interpret this in terms of an electrochemical model. One difficulty was that in hydrochloric acid the incidence of pitting corrosion severely limits the range of electrochemical potential over which studies can be made. The intergranular fissuring question was therefore set aside for the moment in favor of ongoing electrochemical and electronmicroscopic studies of the passive state and of pitting in solutions based on sulfuric acid, to which $\mathrm{NaCl}$ could be added to produce pitting corrosion. Some information has now been developed on electrochemical behavior in these solutions, and the intergranular fissuring phenomenon has been reproduced in them, so that it is now possible to give a preliminary interpretation of this phenomenon. This report presents a review of the relevant information developed in the hydrochloric acid studies, a brief account of pertinent results for sulfuric acid and application of these to the interpretation of this type of attack.

1. Classification of intergranular attack. - A scheme for discussing the relation of pitting to intergranular attack is given in figure 1. In Type 1,

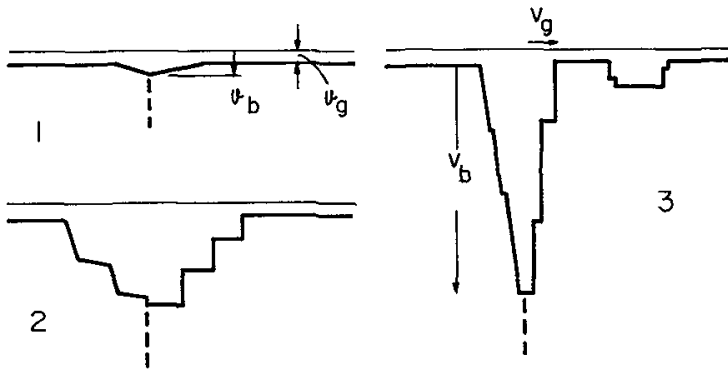

FIG. 1. - Schematic of forms of intergranular pitting attack. 1. Intrinsic attack - no pitting. 2. Preferential pit nucleation, nonpreferential pit growth. 3. Preferential pit growth along boundary to form fissure.

there is no pitting but only preferential attack reflecting the special structure and perhaps composition of the grain boundary which gives a rate of penetration $v_{\mathrm{b}}$ somewhat greater than the rate of uniform attack of the adjacent grain surfaces, $v_{\mathrm{g}}$. A broad shallow groove is formed. In Type 2, after a certain amount of Type 1 corrosion, pits nucleate preferentially at the boundary and grow rapidly but without a preferred growth direction. The pit will then be twice as broad as deep, or approximately hemispherical. In Type 3, pits nucleate (at the same time) at the grain boundary and within the grain, but there is for some reason a much higher rate of pit growth parallel to the boundary, $V_{\mathrm{b}}$, than normal to it, $V_{\mathrm{g}} . V_{\mathrm{g}}$ represents the rate of pit growth in the grain body and determines the dimensions of the pits within the grains.

2. Observations in $\mathbf{H C l}$. - A number of workers in this system have noted intergranular fissuring, which can cause a coarse grained sheet sample to 
separate into individual grains with more or less pitting attack of the surface $[1,2,3,4,5,6]$. These cases appear to represent the situation depicted above as Type 3 . The purity and heat treatment employed and therefore the metallurgical state varied greatly from one study to another as did the strength of the acid and presumably its purity. The significance of metallurgical state and solute segregation on attack under fissuring or nonfissuring conditions is still not established. Both equilibrium segregation [7] and nonequilibrium segregation [8] have been proposed as influencing boundary attack. In any case, there is strong evidence that the fissuring type of attack is always associated with the presence of copper in the aluminium [6,9] as discussed further below. If copper content is sufficiently low, say $1 \mathrm{ppm}$ or less depending on the duration of the test, Type 3 fissuring attack can be delayed or avoided and only Type 1 attack is obtained, thus permitting examination of the corrosion properties of the boundaries unobscured by superimposed pitting $[10,11]$. Earlier studies of some bicrystals [10] and recent more extensive studies [11] show that the Type 1 corrosion behavior of a high angle boundary in aluminium can vary considerably according to its crystallography (as also demonstrated in high temperature water [12]) ( ${ }^{1}$ ). However, for the present purpose, the view is adopted that the pitting effect in intergranular fissuring is so strong as to be recognizable whether the Type 1 intrinsic corrosion of a boundary is weaker or stronger, so that the fissuring phenomenon can be investigated by examining the various boundaries present in a polycrystalline specimen. In the following, reference is made to data for specimens which had been cold rolled, annealed at $645-650^{\circ} \mathrm{C}$ and quenched in water or in an air stream. Aluminium covering a wide range of purity and of the concentrations of specific elements has been examined, but the questions discussed here can be illustrated through the behavior of lots containing, in ppm, wt., either 21,140 or $600 \mathrm{ppm} \mathrm{Cu}$ together with $10 \mathrm{Fe}$, $30 \mathrm{Si}, 5 \mathrm{Mg}$.

The major variables influencing the rate of intergranular fissuring are illustrated in figure 2 where the penetration time for this attack to progress through a coarse-grained $1.6 \mathrm{~mm}$ sheet with boundaries almost normal to the surface was employed as a rough measure of $1 / V_{b}$. The penetration rate not only increases with copper content but also shows a strong dependence on acid strength. If the acid strength is high enough, the phenomenon may be observed at lower copper contents than those shown, e.g., at $1 \mathrm{ppm} \mathrm{Cu}$ penetration will occur in a few days in $8.1 \mathrm{M} \mathrm{HCl}$.

(1) A review of this work was presented at this Conference by Froment [17].

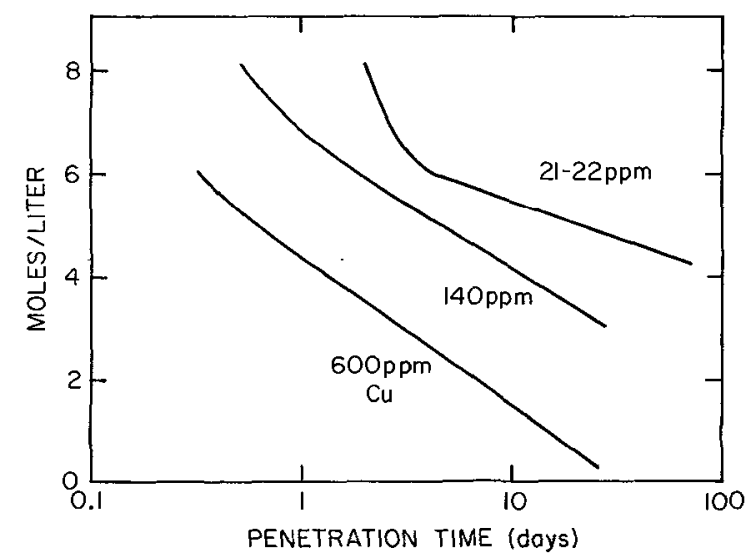

FIG. 2. - Time for intergranular fissuring penetration of $1.6 \mathrm{~mm}$ sheet vs. $\mathrm{HCl}$ concentration for three copper contents [6].

The morphology of the fissuring attack is most effectively observed at a point shortly after it has begun where a limited amount of Type 3 intergranular fissuring (and some intragranular pitting) has been superimposed on Type 1 attack. Such specimens may appear at low magnification as in figure $3 c$, with narrow intergranular fissures. The question whether there is preferential pit nucleation or growth is investigated by examining pit distributions and dimensions at various times. Note must be taken that transient pits are formed concurrent with Type 1 attack even in the passive state. These are much less accessible to study in $\mathrm{HCl}$ than in $\mathrm{H}_{2} \mathrm{SO}_{4}$, where the specimen remains passive if no $\mathrm{Cl}-$ is added. Figure $3 a$, for $\mathrm{H}_{2} \mathrm{SO}_{4}$, represents a nonfissuring situation with shallow transient pits visible at low magnification and serves to illustrate one way of examining possible preferential grain boundary pit initiation (Type 2) tendencies.

The stages of corrosion are illustrated in figure 4 , which displays total corrosion vs. time as determined by measuring the volume of hydrogen gas evolved by the cathode reaction. There is an initial period of approximately constant corrosion rate during which Type 1 attack occurs followed by a stage of accelerating corrosion associated with nucleation and growth of Type 3 attack [13]. The overall rate of pitting attack increases strongly with acid strength and this attack starts sooner, but pitting and fissuring will develop at lower acid concentrations given sufficient time.

3. Electrochemical studies in sulfuric acid. - The growth of pits in aluminium is associated with a certain minimum electrochemical potential, the pitting potential, $E_{\mathrm{p}}$, which is a function of $\mathrm{Cl}^{-}$ concentration [14]. In aluminium containing copper, the corrosion potential, $E_{\text {corr }}$, rises with time, as more effective cathodes are provided by the copper introduced by corrosion. In solutions containing $\mathrm{Cl}^{-}, E_{\text {corr }}$ rises until it reaches $E_{\mathrm{p}}$ and then remains at this value. In figure 5 , the $E_{\text {corr }}$ in 


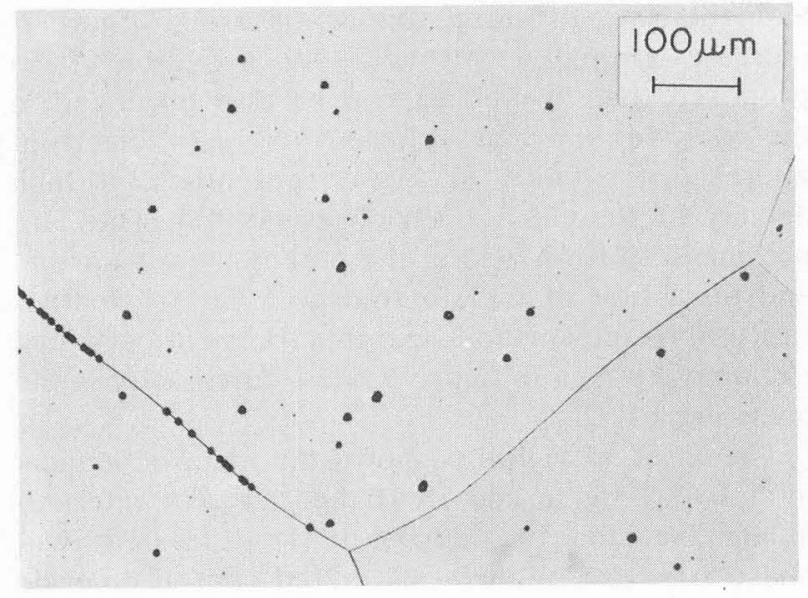

a)

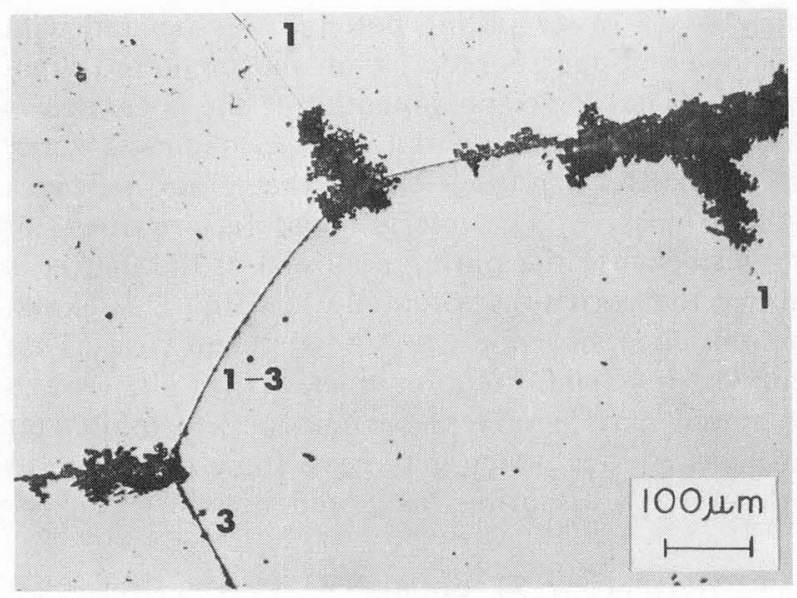

b)

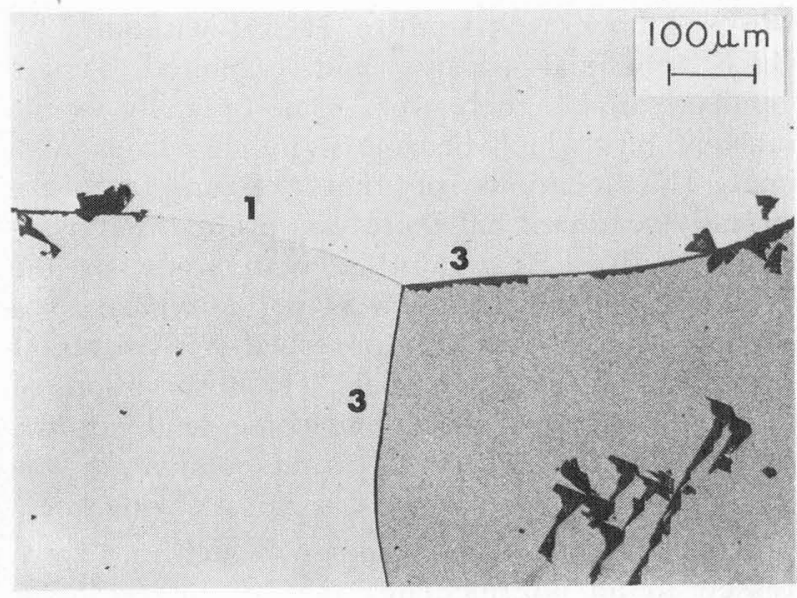

c)

FIG. 3. - Corrosion microstructures of aluminium contain-

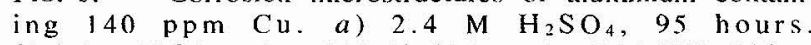
b) $2.4 \mathrm{M} \mathrm{H}_{2} \mathrm{SO}_{4}+1.0 \mathrm{M} \mathrm{NaCl}, 80$ hrs. c) $4.7 \mathrm{M} \mathrm{HCl}, 26$ hrs.

$\mathrm{H}_{2} \mathrm{SO}_{4}$ without $\mathrm{Cl}^{-}$rises very slowly for aluminium with $21 \mathrm{ppm} \mathrm{Cu}$ and considerably faster at $140 \mathrm{ppm} \mathrm{Cu}$. When $1.0 \mathrm{M} \mathrm{Cl}^{-}$is added, $E_{\text {corr }}$ rises more rapidly, attains the pitting potential and remains there as pits nucleate and grow. The

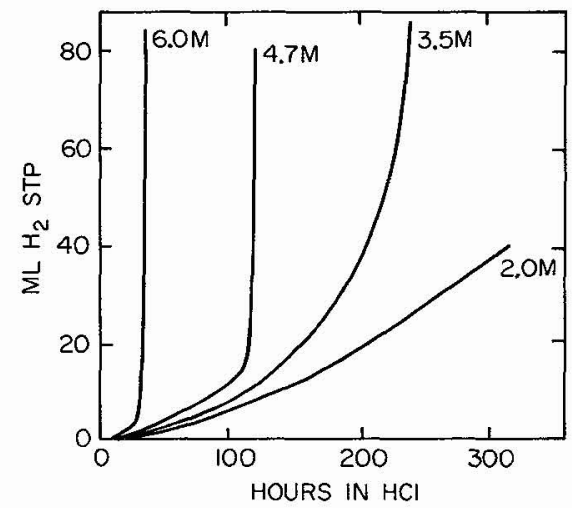

FIG. 4. - Gasvolumetric measurement of total corrosion vs time for aluminium containing $140 \mathrm{ppm} \mathrm{Cu}$ at four concentrations of $\mathrm{HCl}[13]$.

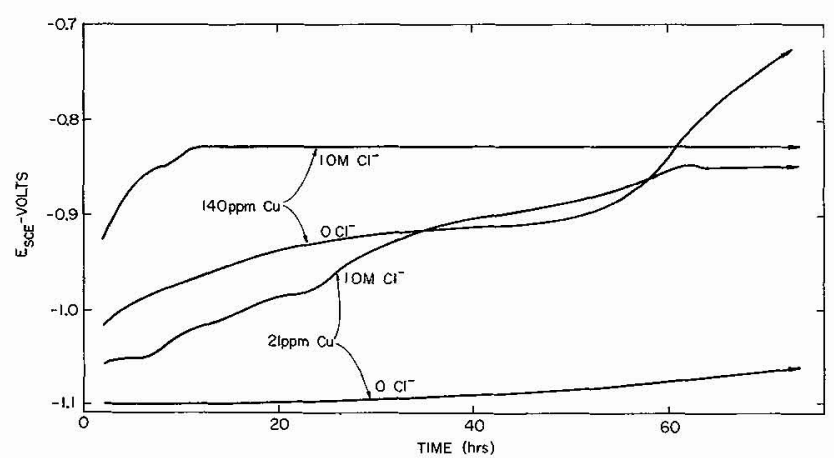

FIG. 5. - Corrosion potential (SCE) vs. time for aluminium with 21 or $140 \mathrm{ppm} \mathrm{Cu}$ in $2.4 \mathrm{M} \mathrm{H}_{2} \mathrm{SO}_{4}$ containing 0 or $1.0 \mathrm{M} \mathrm{NaCl}$.

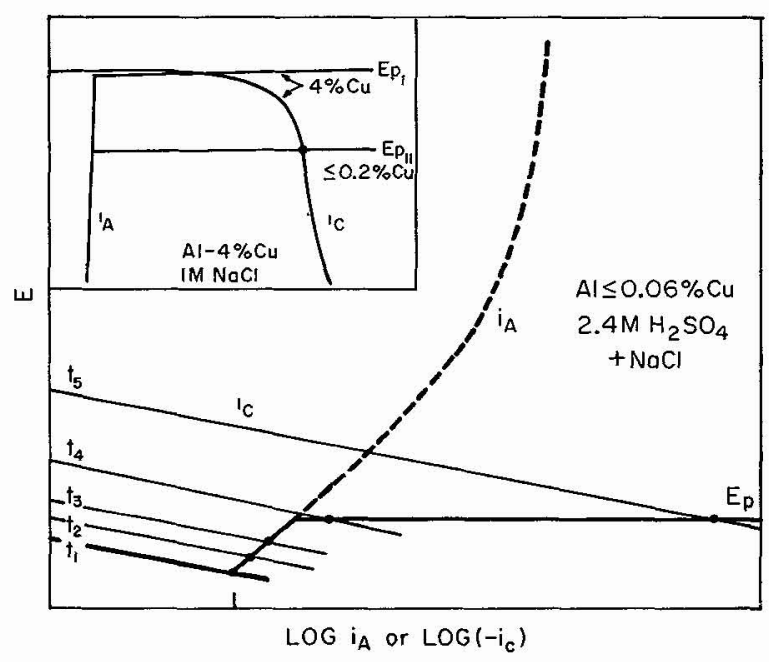

FIG. 6. - Schematic Evans Diagram for single-phase Al containing $\mathrm{Cu}$ in $2.4 \mathrm{M} \mathrm{H}_{2} \mathrm{SO}_{4}+\mathrm{NaCl}$ depicting the changes in corrosion potential and current density with time produced by changes in the cathodic partial current density. Inset-model of Galvele and DeMicheli [16] for intergranular corrosion of two-phase $\mathrm{Al}-4 \% \mathrm{Cu}$ alloys in aerated $1.0 \mathrm{M} \mathrm{NaCl}$.

electrochemical situation is interpreted in figure 6 , which is a schematic Evans diagram guided in part by polarization and other studies on aluminium containing up to $600 \mathrm{ppm} \mathrm{Cu} . E_{\text {corr }}$ and $i_{\text {corr }}$ are determined by the intersection of the partial anodic 
curve, $i_{\mathrm{A}}$, and the partial cathodic curve $i_{\mathrm{C}}, i_{\mathrm{A}}$ would follow the dashed line in the absence of $\mathrm{Cl}^{-}$, but when this ion is present it breaks at $E_{\mathrm{p}}$. Upon immersion in the acid at $t_{1}, i_{C}$ is initially low reflecting the low rate of cathode reactions on pure aluminium due mainly to the high electronic resistance of the oxide film. As corrosion proceeds, the reduction on the aluminium of the copper ion introduced by corrosion yields patches of metallic copper, which provide cathodes of lower hydrogen overpotential and $i_{\mathrm{C}}$ rises with time. When $E_{\text {corr }}$ reaches $E_{\mathrm{p}}$ the pit anodes are unpolarizable and corrosion is under cathodic control. The increase in corrosion rate with time is determined by the increase in the area of the copper patches and the acceleration of corrosion is high because additional copper patches are being provided at a rate proportional to the high corrosion current density. The process is autocatalytic and is consistent with the behavior in $\mathrm{HCl}$ (Fig. 4) [13].

The chloride ion is thought to play a special role here $\left({ }^{2}\right)$. If the copper ion is reduced to metallic copper on the external surface of the oxide film, it will be relatively ineffective in raising $i_{\mathrm{C}}$. Work in $\mathrm{HCl}$ has shown that $\mathrm{Cu}^{2+}$ added to the acid has a much smaller effect on the corrosion rate than the same amount of copper added by corrosion [13]. To produce effects as large as those observed, it is reasoned that some of the copper must be reduced in metallic contact with the aluminium. A film-free aluminium surface will not be available except within a stable or a transient pit and it will be acting as an anode. The situation visualized is shown schematically in figure 7 . There will be a potential

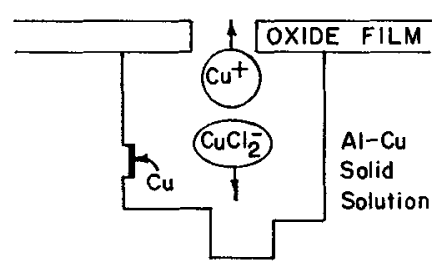

FIG. 7. - Schematic of the role of chloride in forming copper cathode patches within a pit.

gradient in the pit which drives anions inward to neutralize the excess positive charge from aluminium dissolution [14]. A positive ion (i. e., $\mathrm{Cu}^{+}$or $\mathrm{Cu}^{2+}$ ) will tend to move away from the anode and out of the pit. In the presence of $\mathrm{Cl}^{-}$the $\mathrm{CuCl}_{2}^{-}$ anion can be formed, and the copper in this ion will move toward an anode position where it can be reduced in metallic contact with the aluminium. This action of $\mathrm{Cl}^{-}$is one reason why in $\mathrm{HCl}$ the autocatalytic acceleration of corrosion, figure 4 ,

(2) It is assumed, without discussing the justification, that copper atoms in the dilute alloy isolated by oxidation of the surrounding aluminium can temporarily enter the solution as ions. and the rate of intergranular fissuring, figure 2, increase strongly with acid concentration. It is proposed that this effect can be also produced in the passive state at transient pits. In electronmicroscope studies at higher potentials, a high density of these has been observed [15]. They are presumed to form also at the potentials of figure 5, and an action of $\mathrm{Cl}^{-}$to transport $\mathrm{Cu}^{+}$to temporarily film-free surfaces within a transient pit would explain why $E_{\text {corr }}$ in figure 5 rises much faster in the presence of $\mathrm{Cl}^{-}$.

The inset of figure 6 shows the electrochemical model of Galvele and DeMicheli [16] for intergranular corrosion of improperly heat treated twophase Al-4 \% Cu alloys in aerated neutral chloride solution. The essence of their explanation is that the solute-depleted zone bordering the grain boundary has a lower pitting potential (associated with its lower copper content) than the unaltered grain matrix. The corrosion potential of the specimen is then the pitting potential of the depleted zone, which suffers pitting while the grain surfaces remain passive. The intergranular fissure does not widen because the pitting potential of the matrix is above the corrosion potential $\left(V_{\mathrm{g}} \sim 0\right)$. This explanation does not apply to the present case. That copper in solid solution raises the pit growth potential may signify some tendency to inhibit pit growth, an idea which may have some relevance to intergranular fissuring, as noted below.

4. Morphology of pitting. - Observations are illustrated here for the aluminium containing 140 ppm Cu.

In specimens exposed to $\mathrm{H}_{2} \mathrm{SO}_{4}$ without $\mathrm{Cl}-$, which remained passive and exhibited Type 1 boundary attack, there were some optically visible transient pits which became more numerous with time. The locations of these, figure $3 a$, were normally scattered but there was preferential association with a few of the boundaries in the specimen. This distribution is not untypical of a number of distributions observed for different copper contents and potentials. The observations of this type suggested that while some tendency for preferential pit initiation at grain boundaries was often present this tendency was not a strong one.

Figure $3 b$ shows a specimen which has progressed to an intermediate stage of intergranular fissuring in $\mathrm{H}_{2} \mathrm{SO}_{4}$ with $1.0 \mathrm{M} \mathrm{Cl}^{-}$. Although a few of the boundaries are still in the Type 1 stage, it is seen that intergranular pitting from grain junctions has progressed considerably while pits within the grains have remained small. Boundaries appearing as narrow dark bands are mainly deeply fissured, as revealed by scanning electron microscopy, figure 8 . It was desired to conduct a quantitative examination of the fissures by taking stereo pairs with a near-normal beam, but the fissures were usually too 
narrow to obtain an image from their bases because of the loss of the electric field there. The wide pits at triple junctions were often favorable for revealing lower parts of fissures, but even these wide pits provided a limited view because the pitting did not leave a clear cavity but a skeleton of oxide and metal which obscured the pit base. In figure 8 ,

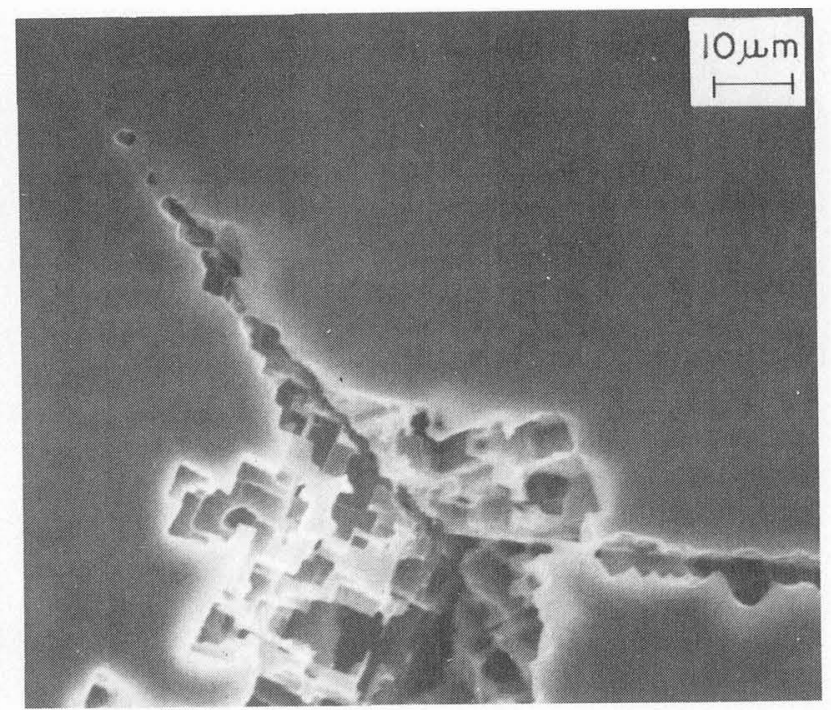

FIG. 8. - Secondary electron image at near normal beam incidence of intergranular fissuring in the specimen of figure $3 b$.

evidence of lateral growth of a fissure, tunneling and reemerging at the surface is seen from the junction toward the upper left.

Figure $3 c$-shows a specimen in which intergranular fissuring has progressed to a moderate degree in $4.7 \mathrm{M} \mathrm{HCl}$. The attack at the two Type 3 boundaries has quite a uniform appearance along their length. Scanning electron microscopy, figure 9, showed the detail at the surface but again failed to reveal the bases of the fissures. As far as one could determine, the intergranular fissuring here had basically the same character as that in figures $3 b$ and 8 and the phenomenon in both solutions was of Type 3 .

5. Further discussion. - These observations demonstrated that the production of intergranular fissuring in single phase aluminium containing copper was not a unique property of hydrochloric acid. It did require $\mathrm{Cl}^{-}$in sufficient amount - ir $\mathrm{H}_{2} \mathrm{SO}_{4}, 0.1 \mathrm{M} \mathrm{Cl}^{-}$produced slower and much les: selective attack than $1.0 \mathrm{M} \mathrm{Cl}^{-}$. According to the view presented here, the role of $\mathrm{Cl}^{-}$is (1) to make pitting possible (2) to transport copper ions toward anodes where they can form effective copper cathodes in metallic contact with the substrate. Efficient cathodes are required in order that the corrosion potential should rise to the pitting potential and that the rate of pitting should be high. One may ask if copper has another role besides that of the source material for the cathodes.

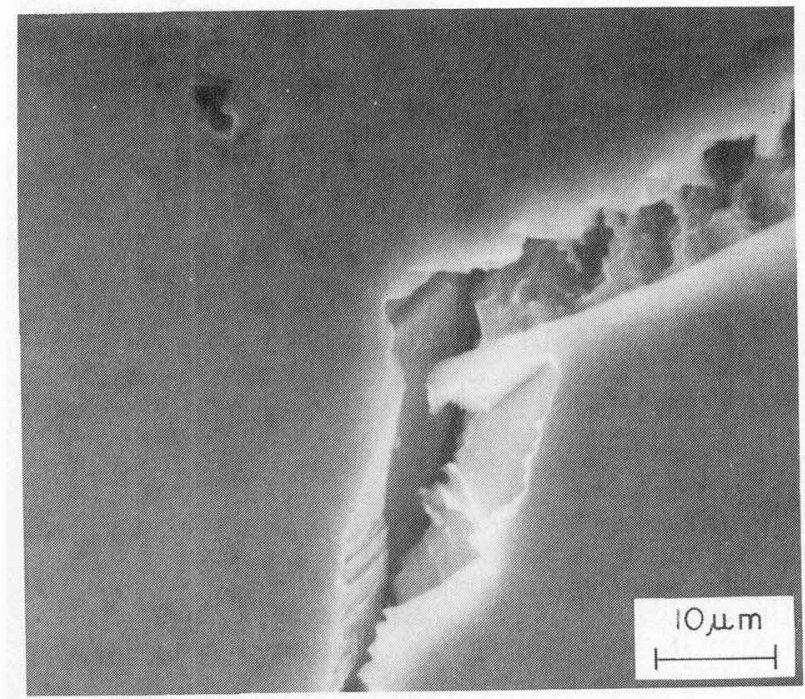

FIG. 9. - Secondary electron image at near-normal beam incidence of intergranular fissuring in the specimen of figure $3 c$.

In intergranular fissuring, the reason why the rate of pitting should be so much higher down the boundary in a single-phase material is not immediately apparent. It might be thought that the pitting reaction is so strong as to take little account of relatively small differences in anode properties between boundary and grain. There seem to be two possible types of explanation. In free corrosion at the pitting potential the cathodes supply a certain current for which various parts of the pit surface compete. Under these conditions, a small advantage may permit the grain boundary part of the pit surface to acquire more than its share of the current and thus to short circuit the remainder of the pit surface. A second possibility is to suppose that the effect of copper content to raise the pitting potential implies some inhibiting action on pit growth. If the inhibiting action is such that pit growth has to be reactivated periodically, the small advantage possessed by a grain boundary may shorten the time required for reactivation and yield a higher average growth rate along the boundary. Electrochemical studies, now in progress, aimed at understanding the effect of copper content on pit growth may help to resolve this question.

It is seen that the application of electrochemical ideas to this problem can not be done in a routine fashion and will have to be based on specific models for the passive state and for pitting. Experiments to develop these models usually employ potentiostatic or galvanostatic procedures rather than free corrosion. From experiments performed thus far, the relations between grain boundaries and pitting tend to be different under these conditions and have not been discussed here.

Acknowledgments. - This work was supported by the Department of Metallurgy and Mining Engineering, by the Energy Research and Deve 
lopment Administration through the Materials Research Laboratory, and by the U.S. Army Research Office. The author is indebted to
T. R. Odom for making available some work in progress and to $P$. R. Bhowal for the scanning electron microscope study.

\section{References}

[1] Rohrman, F. A., Trains. Electrochem. Soc. 66 (1934) 229.

[2] Lacombe, P. and Yannaquis, N., Rev. Métall. 45 (1948) 68.

[3] Metzger, M. and Intrater, J., Nat. Advisory Committee for Aeronautics (U.S.A.), Techn. Note No 3281 (1955).

[4] Bussy, P., Publications Scientifiques et Techniques du Ministère de l'Air, No 325 (1957).

[5] Montariol, F., Corros. Anticorros. 6 (1958) 101.

[6] ARORa, O. P., Ramagopal, G.'R. and METzGer, M., Trans. Met. Soc. AIME 224 (1962) 541.

[7] Perryman, E. C. W., Trans. AIME 197 (1953) 711.

[8] AuST, K. T. and IWAO, O., Localized Corrosion, NACE, Houston (U.S.A.) (1974) 62.

[9] Hendrickson, L. E. and Metzger, M., Trans. Met. Soc. AIME 242 (1968) 2329.
[10] Arora, O. P. and Metzger, M., Trans. TMS-AIME 236 (1966) 1205.

[11] Froment, M. and Vignaud, C., Mét. Corr. Ind. 581 (1974) 2 and 582 (1974) 67.

[12] Boos, J. Y. and Goux, C., Localized Corrosion NACE, Houston (U.S.A.) (1974) 556 ; BOOS, J. Y. and GoUX, C., L'Hydrogène dans les Métaux 1.

[13] METZGer, M. and ARORA, O. P., Trans. TMS-AIME 227 (1963) 1305.

[14] Kaesche, H., Z. Phys. Chem. N. F. 34 (1962) 87

[15] ZaHAVI, J. and METZGER, M., J. Electrochem. Soc. 121 (1974) 268

[16] Galvele, J. R. and DeMicheli, S. M., Corros. Sci. 10 (1970) 759 .

[17] Froment, M., J. Physique Colloq. 36 (1975) C4-371.

\section{DISCUSSION}

J.-Y. Boos : Vous avez montré l'influence importante du cuivre. D'après votre interprétation, on peut s'attendre à observer un même effet avec du cuivre contenu dans le métal, ou avec du cuivre ajouté à la solution. Est-ce le cas ?

M. Metzaer: Studies in $\mathrm{H}_{2} \mathrm{SO}_{4}$ are still in progress but we looked earlier at this question in $\mathrm{HCl}$ and found that copper furnished by corrosion had a much larger effect than the same amount added to the acid as $\mathrm{Cu}^{2+}$. Our explanation is that patches of copper are more effective when they are formed not on the external surface of the oxide film but directly on the aluminium substrate and that this is more likely when the source of the copper is corrosion of the solid solution. The process by which the patches are formed and the role of $\mathrm{Cl}^{-}$in it was discussed from the assumption that there is dissolution and redeposition of some copper in the solid solution (rather than merely preferential dissolution of aluminium and agglomeration of the remaining copper atoms into patches). An analysis of the path of copper during corrosion of the solid solution involves consideration of explicit models of the processes of film formation and dissolution and of transient pitting and repassivation and has not been attempted here.

B. RALPH : My question is simply haw and why does the oxide film break down preferentially over the grain boundary so that pits are formed ? I would have imagined that the oxide film would have been thicker over the boundary regions.

M. MetzGer: These questions can not be answered from the present work, which was interpreted on the basis that stable pit nucleation could occur anywhere and there was selective growth of those stable pits staddling boundaries. In electronmicroscopic studies of anodic film growth on $99.999 \% \mathrm{Al}$, breakdown did not appear to be the critical step in pitting because there was a high frequency of transient pitting, apparently at random locations [15]. Any tendency for nucleation of stable pits to occur preferentially at boundaries was attributed to the extra stimulation given by the boundaries to the growth of those pit embryos which happened to intersect them (Zahavi and Metzger. Localized Corrosion, NACE, Houston (1974), 547). Other studies are in progress. 
M. Froment-A. Desestret : Pensez-vous que le potentiel de la réaction anodique puisse rester constant compte tenu de l'acidification progressive du fond des piqûres ? Celles-ci doivent contenir des concentrations importantes d'acide chlorhydrique. La concentration élevée en ions $\mathrm{H}^{+}$peut également modifier la réaction cathodique et éventuellement provoquer une pénétration, et une fragilisation par l'hydrogène.

M. METZGER : The potential measured external to the pit is observed to remain constant for long periods (at least weeks). A steady state is apparently established (so long as the composition of the bulk solution does not change with time)." The composition of the solution within the pit is different from that outside, but this difference is established relatively rapidly and then remains constant (as judged, for example, from Edeleand's Microscope observations of pit growth in $3 \%$ $\mathrm{NaCl}$ ). We do not know the composition of the pit anolyte nor the mechanism of pit growth. Now high acid concentration in the pit is not itself of concern (the bulk concentrations we used were already high). What is thought to be important is a low potential in the pit. This is important for hydrogen ion reduction, and $I$ agree that this could be important in one way or another. On the other hand, our SEM studies of pits in aluminium do not suggest embuttlement or mechanical damage as a factor in pit growth. 